\title{
Mid-term Clinical Outcomes of Stand-alone Posterior Interbody Fusion with Rectangular Cages: A 4-year-minimum Follow-up
}

\author{
Kyung Rae Cho, Sun-Ho Lee, Eun Sang Kim, Whan Eoh \\ Department of Neurosurgery, Samsung Medical Center, Sungkyunkwan University School of Medicine, Seoul, Korea
}

Objective: We sought to determine minimum 4 years of clinical outcomes including fusion rate, revision rate and complications of patients who underwent placement of rectangular stand-alone cages.

Methods: Thirty-three cases of degenerative spine that had been followed for at least 4-years were reviewed retrospectively. Cages were inserted at L4-L5 level or L5-S1 in 27 or in 6 cases respectively. Visual analogue scale (VAS), Odom's criteria, fusion rate, intervertebral disc height and lumbar lordosis were determined pre- and post-operatively on standing $\mathrm{x}$-rays. Amount of intra- and postoperative blood loss, total volume transfused, duration of surgery and perioperative complications were also evaluated.

Results: The mean VAS score of back pain and sciatica were improved from 8.0 and 7.0 points to 3.4 and 2.4 during 1 years follow-up visit and the scores was raised gradually. Also, during the follow-up, $94 \%$ of patients showed excellent or good outcomes by the Odom's criteria. Intervertebral disc height was increased from $8.2 \pm 1.4 \mathrm{~mm}$ to $9.2 \pm 1.9 \mathrm{~mm}$ at the first year of follow-up, however, found to be decreased and stabilized to $8.3 \pm 1.8 \mathrm{~mm}$ after 2 years. The fusion rate was approximately $91 \%$ after 4 year postoperative. The segmental angle of lordosis was increased significantly by two years but it was not maintained after four years. A statistically insignificant change in total lumbar lordosis was also observed. Three patients $(9 \%)$ had experienced perioperative complications.

Conclusion: The use of rectangular stand-alone cages for posterior lumbar interbody fusion (PLIF) resulted in a various degree of subsidence and demonstrate very low complication rate, high functional stability and improved clinical outcomes in patients with degenerative lumbar disc disease.

Key Words: Posterior lumbar interbody fusion $\cdot$ Stand-alone cage $\cdot$ Rectangular cage

\section{INTRODUCTION}

Spinal fusion is a popular management option in the management of degenerative conditions of the lumbar spine ${ }^{4)}$. Since it was first described by Briggs and Milligan in 1944, the posterior lumbar interbody fusion (PLIF) has some distinct theoretical advantages over posterolateral techniques as a fusion strategy ${ }^{4}$. The benefits of the PLIF are securing the fixation of vertebral body, maintaining the normal intervertebral space and supporting the anterior column in charge of $80 \%$ of weight-bearing out of the vertebral column, thus providing

- Received: April 30, 2013 - Revised: September 3, 2013

- Accepted: September 5, 2013

Corresponding Author: Whan Eoh, MD, PhD

Department of Neurosurgery, Samsung Medical Center, Sungkyunkwan

University School of Medicine, 50 Irwon-dong, Gangnam-gu, Seoul

135-710, Korea

Tel: 82-2-3410-3491, Fax: +82-2-3410-0048

E-mail:w.eoh@samsung.com satisfactory bone fusion while maintaining biomechanical stability ${ }^{22,26-28)}$. Various kinds of spinal implant cage devices have been designed to provide a relatively simple and effective technique for implementing PLIF and to improve fusion rates by acting as a structural support while biological fusion occurs ${ }^{8,14)}$. Recently several authors have reported that the cage geometry, such as rectangular, trapezoid or cylindrical, has a significant impact on the alignment of the lumbar spine after instrumented PLIF ${ }^{9,13,20)}$. These authors considered wedgeshaped, trapezoid cages significantly increase segmental lordosis, enhancing lumbar lordosis, and therefore should be preferred for restoring sagittal alignment in instrumented PLIF procedures ${ }^{9,13)}$.

We have utilized rectangular cages for PLIF since 1995. In the present study we investigated whether the lumbar sagittal alignment can be obtained within normal range in patients who have undergone PLIF with stand-alone cages, which have no intrinsic contour to induce lordosis and asse-ssed not only the firm bone fusion but also the clinical results of those patients. Here, we had an opportunity to review the mid-term follow- 
up outcomes from patients who underwent placement of rectangular stand-alone cages by a single, independent surgeon.

\section{MATERIALS AND METHODS}

\section{Patient Selection}

Patients with back pain with or without radiating pain who underwent PLIF with stand-alone rectangular cages between 1996 and 2004 have reviewed retrospectively. Radiographic and clinical follow-up of patients was reviewed in 33 patients who were followed-up at least 4 years after surgery. Thirteen patients had failed back surgery syndrome after primary disc surgery, 9 had herniated intervertebral disc, 7 had degenerative disc disease (DDD), 3 with spinal stenosis, and 1 had spondylolisthesis. The cages used including Ogival Interbody Cage (OIC), Carbon Cage (CC), CH Cage, Poly-Ether-Ether- Ketone Cage (PEEK).

A total 33 patients in age range of 22 to 74 years with the mean of 46.2 years enrolled into the study. The summary of patient demographic data is listed in Table 1 . Surgery was performed on patients who mainly had symptomatic degenerative disc disease showed that definite low signal intensity on T2 MRI, definite decrease in the intervertebral disc height in one or two contiguous lumbar levels, unresponsive to conservative treatment and no greater than Grade I spondylolisthesis. Patients were excluded from the study if they had any symptomatic disc disease at a level other than L4-L5 or L5-S1 or a severe medical condition.

\section{Surgical Procedure}

All surgical procedures were carried out by a single spine surgeon. Patients underwent total laminectomy and medial

Table 1. Demographic data on the patients

\begin{tabular}{lll}
\hline & & \multicolumn{1}{c}{ no } \\
\hline Patients no. & & 33 \\
Sex (M:F) & $16: 15$ \\
Age (yr) & $41.3(22-74)$ \\
Level of implant & L4-L5 & 27 \\
& L5-S1 & 6 \\
Level of used cage & $\mathrm{CH}^{-}$ & 8 \\
& $\mathrm{CC}^{+}$ & 12 \\
& $\mathrm{OIC}^{+}$ & 8 \\
& PEEK $^{\S}$ & 5 \\
\hline
\end{tabular}

"OIC (Ogival Interbody Cage: Stryker Howmedica Osteonics, Mahwah NJ, USA), ${ }^{\dagger}$ CC (Carbon fiber Cage: De Puy-Acro med Co., Raynham, MA, USA), ${ }^{\ddagger} \mathrm{CH}$ Cage (Spine-Tech, Minneapolis, MN, USA), §PEEK (Poly-Ether-Ether-Ketone Cage, Stryker Howmedica Osteonics, Mahwah NJ, USA) facetectomy to visualize thecal sac and nerve roots to make sure decompression is sufficient. And bilateral discectomy was held using shaver, then posterior lumbar interbody arthrodesis with two cage devices were implanted at either the L4-L5 or L5-S1 lumbar interspace. Four kinds of rectangular cages were used in our series namely Ogival Interbody Cage (OIC: Stryker Howmedica Osteonics, Mahwah NJ, USA), Carbon fiber (CC: De Puy-Acro med Co., Raynham, MA, USA), CH Cage (Spine-Tech, Minneapolis, MN, USA), Poly-Ether-EtherKetone (PEEK, Stryker Howmedica Osteonics, Mahwah NJ, USA) cage. These cages were without any lordotic angle such as 0 degree and have little or no intrinsic ability to induce a lordotic contour. The chamber of cages was filled with autologous cancellous bone obtained from the lamina or iliac crest except 2 cases used allograft bone chip. Every patient had orthothic device for minimum 2 months. The results from all the studies were pooled and analyzed independently to define the effects of the surgical technique on the surgical outcome, hospital stay, and the mid-term clinical and radiographic outcomes.

\section{Assessment of Clinical and Radiographic Outcome}

Through pre- and post-operative direct evaluation at 1, 6, 12 and 24 months on their hospital visit or a telephone survey, the severity of low back or leg pain was evaluated by a Visual Analogue Scale (VAS) and the clinical outcomes were examined by an Odom's criteria.

Plain radiographs were measured and reviewed by single spine surgeon at pre- and immediate post-operative state, postoperative one year, two years and after in alternate years. Intervertebral height was measured at the mid-point of both lines which are connected from anterior to posterior end plates of upper and lower vertebral bodies on the lateral plain radiographs, total lumbar lordosis was measured from the bottom of T12 to the bottom of L5 as described by Cobb ${ }^{355}$. The degree of segmental lordosis at the site of surgery was measured from the lower endplate of the upper segment to the upper endplate of the lower segment. Using the simple lumbar lateral X-ray with flexion-extension view, stability and the status of fusion was assessed. Thin-cut computed tomography scans with sagittal and coronal reconstructions through the fusion construct were obtained as necessary. Fusion was defined when all the conditions below were fulfilled. Bridging bone connecting the adjacent vertebral bodies either through the implants or around the implants, $<5^{\circ}$ of angular motion, $\leq 3 \mathrm{~mm}$ of translation, and an absence of radiolucent lines around $>50 \%$ of either implant. Secondary lumbar surgical procedures performed subsequent to the index operation because of a suspected nonunion, regardless of the radiographic 
findings, were classified as second surgery failures and fusion failures ${ }^{5)}$.

\section{Statistical Analysis}

All statistical analysis was carried out using SPSS (version 17.0, SPSS Inc., Chicago, IL). The changes in preoperative and postoperative radiological findings were analyzed using the paired t-test. The Mann-Whitney test was used. Statistical significance was determined when $\mathrm{p}$ values were less than 0.05 .

\section{RESULTS}

\section{Patient Demographics}

Thirty-three patients who were followed up at least four years, twelve patients (36.3\%) were followed more than 8 years. Average surgery time was $236.8 \pm 53.1$ minutes, average intraoperative blood loss was $334.8 \pm 292.2 \mathrm{~mL}$, and average hospital length of stay was $10.8 \pm 3.3$ days. All of the patients used autologous bone chip. Further, thirty (90.9\%) patients of them used autologous iliac bone and 3 (9.1\%) used autologous and allograft mixed bone chip.

Three patients (9.1\%) experienced perioperative complications including dura tearing which occurred two times, however, there were no CSF leakages or no meningitis post-surgery. One patient had aggravation of stenosis at L3-4 level that needed operation. There were no other clinical complications including neurologic deficit, infection, hematoma formation, hardware failure or cases of re-operations were observed dur-

Table 2. Changes of visual analogue scale and odom's criteria

\begin{tabular}{|c|c|c|c|c|c|}
\hline \multirow{2}{*}{\multicolumn{2}{|c|}{ Parameter }} & \multicolumn{4}{|c|}{ Follow period } \\
\hline & & Pre-OP & $1 \mathrm{yr}$ & $4 \mathrm{yr}$ & $>8 \mathrm{yr}$ \\
\hline \multirow[t]{3}{*}{ VAS } & Back pain & $8.0 \pm 2.9$ & $3.4 \pm 3.0$ & $2.2 \pm 3.0$ & $3.7 \pm 2.5$ \\
\hline & Leg pain & $7.1 \pm 3.1$ & $2.5 \pm 2.8$ & $1.4 \pm 2.8$ & $3.1 \pm 2.0$ \\
\hline & Excellent & & 30 & 36 & 24 \\
\hline \multirow{3}{*}{$\begin{array}{l}\text { Odom's } \\
\text { criteria } \\
(\%)\end{array}$} & Good & & 61 & 58 & 67 \\
\hline & Fair & & 6 & 3 & 0 \\
\hline & Poor & & 3 & 3 & 1 \\
\hline
\end{tabular}

ing the follow-up period.

\section{Clinical Outcomes}

The mean score on the VAS of back pain found to be improved from $8.0 \pm 2.9$ points during the preoperative period to $3.4 \pm 3.0$ points at one year postoperative and decreased to $2.1 \pm 3.0$ and $3.5 \pm 2.7$ at postoperative 4 and more than 8 years, respectively. The VAS of sciatica was reduced from $7.1 \pm 3.1$ at preoperative to $2.5 \pm 2.8$ post 1 year, and it was reduced to $1.5 \pm 2.8$ and $3.1 \pm 2.6$ at the same periods, respectively. At their last follow-up, about $94 \%$ of patients showed excellent or good outcomes on Odom's criteria (Table 2).

\section{Radiographic Outcomes}

The results on the change of the intervertebral disc height, segmental lordosis and total lordosis are also listed in Table 3. The mean intervertebral disc height was $8.2 \pm 1.4 \mathrm{~mm}$ before surgery and it was increased to $10.7 \pm 1.2 \mathrm{~mm}$ at postoperative and was decreased to $8.7 \pm 1.9 \mathrm{~mm}$ by 2 years and it was stabilized to $8.3 \pm 1.8,8.1 \pm 2.1$ and $8.7 \pm 1.9 \mathrm{~mm}$ at 4,6 and more than 8 years follow-up visit. It was modestly decreased on the final visit compared with postoperative state. The angle of segmental lordosis at the neutral position was increased from $12.1 \pm 4.0^{\circ}$ before surgery to $14.1 \pm 4.4^{\circ}$ by postoperative 1 year. The angle was maintained for two years with no significant difference $(p=0.317)$, but it reduced at 4 year follow up $(p=0.072)$. The angulation of total lumbar lordosis also changed from $32.8 \pm 10.2^{\circ}$ to $35.3 \pm 8.9^{\circ}$ at the same period $(p=0.200)$. But there was not statistically significant difference.

Plain X-rays were analyzed for confirming solid fusion at the out-patient clinic during follow-up period. A total of 30 patients with obvious trabecular bridging on the plain $x$-ray and the fusion rate was $87.9 \%$ at 1 year follow-up. The fusion rates were $91 \%$ at 4 years follow-up.

There was no significant difference of clinical results between 4 types of cages. There was significant difference between 4 types of cages in radiological outcome. CC had excellent radiological outcome in disk height, segmental lordosis and total lordosis during 4 years of follow-up. Other cages also seemed to improve in radiologic outcome but we could not find statistical significant difference (Table 4).

Table 3. Changes of the intervertebral disk height, segmental lordosis, and total lordosis (Mean \pm Standard deviation)

\begin{tabular}{lcccc}
\hline \multirow{2}{*}{\multicolumn{1}{c}{ Parameter }} & \multicolumn{4}{c}{ Follow period } \\
\cline { 2 - 5 } & Pre-OP & $1 \mathrm{yr}$ & $4 \mathrm{yr}$ & $>8 \mathrm{yr}$ \\
\hline Intervertebral Height (cm) & $8.2 \pm 1.4$ & $9.2 \pm 1.9$ & $8.3 \pm 1.8$ & $8.7 \pm 1.9$ \\
Segmental lordosis (degree) & $12.1 \pm 4.0$ & $14.1 \pm 1.42$ & $12.6 \pm 4.6$ & $10.3 \pm 5.8$ \\
Total lumbar lordosis (degree) & $32.8 \pm 10.2$ & $35.3 \pm 8.9$ & $36.0 \pm 8.1$ & $39.6 \pm 10.6$ \\
\hline
\end{tabular}


Table 4. Changes of the intervertebral disc height, segmental lordosis and total lordosis are compared with 4 different cages

\begin{tabular}{|c|c|c|c|c|c|c|c|c|c|c|c|c|}
\hline & \multicolumn{4}{|c|}{ Segmental lordosis } & \multicolumn{4}{|c|}{ Total lordosis } & \multicolumn{4}{|c|}{ Disc height } \\
\hline Cage & Pre op & Post op & $1 \mathrm{yr}$ & $4 \mathrm{yr}$ & Pre op & Post op & $1 \mathrm{yr}$ & $4 \mathrm{yr}$ & Pre op & Post op & $1 \mathrm{yr}$ & $4 \mathrm{yr}$ \\
\hline CC & $11.3 \pm 4.4$ & $14.4 \pm 5.9^{*}$ & $14.2 \pm 4.7^{*}$ & $13.3 \pm 4.4^{*}$ & $28.6 \pm 11.3$ & $34.2 \pm 7.3^{*}$ & $34.7 \pm 8.9^{*}$ & $34.4 \pm 7.1^{*}$ & $7.8 \pm 1.1$ & $10.5 \pm 0.9^{*}$ & $9 \pm 0.9^{*}$ & $8.4 \pm 1.2$ \\
\hline $\mathrm{CH}$ & $14.1 \pm 3.8$ & $13.9 \pm 4.9$ & $14.5 \pm 4.5$ & $13.1 \pm 4.1$ & $32.8 \pm 9.5$ & $33.5 \pm 8.5$ & $35.9 \pm 9.3$ & $36 \pm 7.8$ & $8.4 \pm 1.8$ & $10.8 \pm 1.0^{*}$ & $9.1 \pm 2.1$ & $7.8 \pm 1.6$ \\
\hline $\mathrm{OIC}$ & $13.9 \pm 2.2$ & $15.0 \pm 5.3$ & $16.3 \pm 2.9 *$ & $14.9 \pm 2.5$ & $41.2 \pm 7.1$ & $37.3 \pm 7.8^{*}$ & $41.3 \pm 5.9$ & $42 \pm 7.9$ & $8.8 \pm 0.9$ & $10.8 \pm 1.1^{*}$ & $8.9 \pm 2.4$ & $8.1 \pm 1.9$ \\
\hline PEEK & $7.9 \pm 2.5$ & $7.6 \pm 1.9$ & $10.1 \pm 3.6$ & $6.2 \pm 3.6$ & $29.7 \pm 6.1$ & $30 \pm 6.0$ & $25.9 \pm 4.9$ & $30.4 \pm 7.2$ & $8 \pm 2$ & $10.6 \pm 2.1$ & $10 \pm 3.1$ & $9 \pm 2.9$ \\
\hline
\end{tabular}

OIC (Ogival Interbody Cage: Stryker Howmedica Osteonics, Mahwah NJ, USA), CC (Carbon fiber Cage: De Puy-Acro med Co., Raynham, MA, USA), CH Cage (Spine-Tech, Minneapolis, MN, USA), PEEK (Poly-Ether-Ether-Ketone Cage, Stryker Howmedica Osteonics, Mahwah NJ, USA)

had significant change from pre-operative values $(p<0.05)$
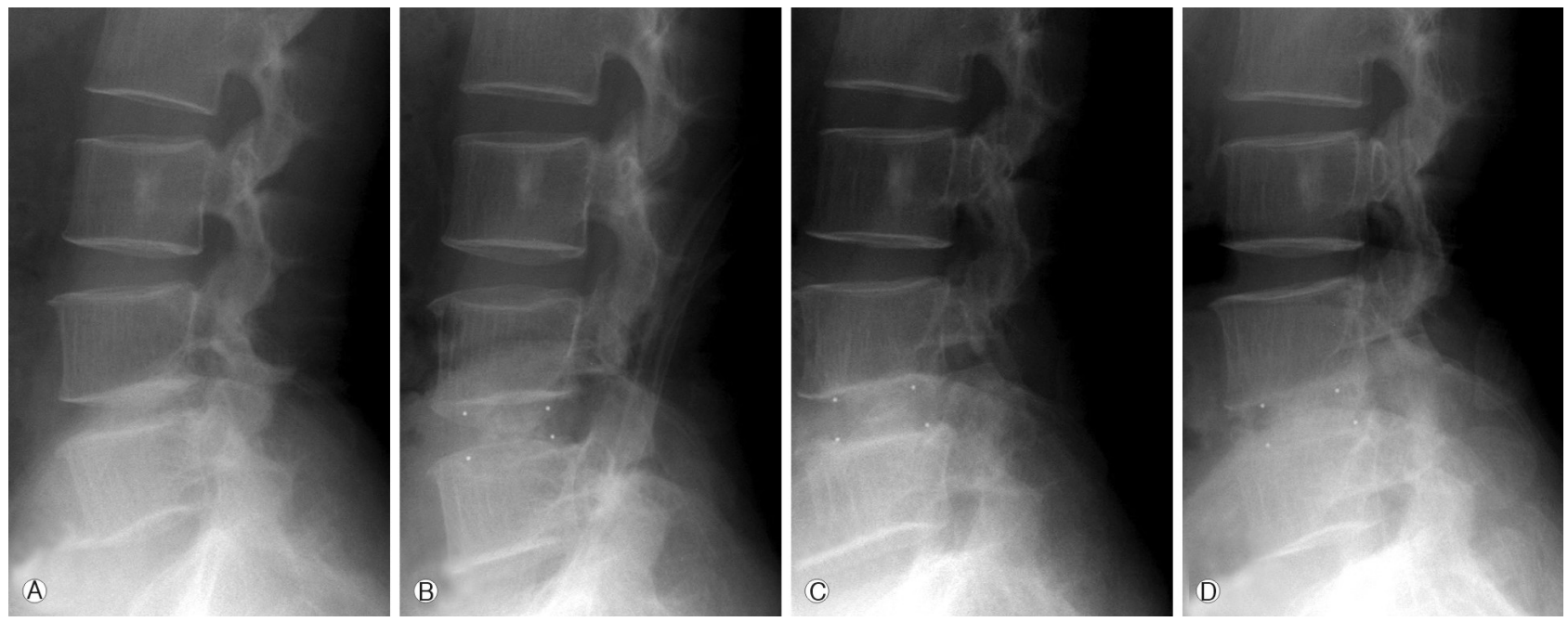

Fig. 1. (A) The height of disc is lower than other level of lumbar disc. (B) After surgery, disc height is restored with cage inserted bilaterally. (C) A year after surgery, disc height is still remained and bony fusion is made. (D) Four years after surgery, without subsidence or retropulsion fusion was firmly made.

\section{Illustrative Case}

\section{Case I}

Fourty nine years old male who complained with left leg pain had disc herniation at lumbar 4-5 level and underwent PLIF with CC cage (Fig. 1). Height of disc space was $9.5 \mathrm{~mm}$ before surgery and height rise up to $12 \mathrm{~mm}$. After a year, height slightly decreased to $11 \mathrm{~mm}$ and the height maintained in $10 \mathrm{~mm}$ during 7 years of follow-up. Segmental lordosis before surgery was $13.5^{\circ}$ which merely changed after surgery. But after 7 years it decreased to $7^{\circ}$. Total lordosis before surgery was measured as $42.9^{\circ}$ which decreased in $33^{\circ}$ after surgery and changed minimally till 7 years of follow-up. His VAS score decreased from 9 to 2 and excellent in Odom's criteria.

\section{Case II}

Sixty one year-old lady suffered from her both buttock and leg pain for 20 years. Her symptom aggravated since 2 years before admission, and diagnosed to have spinal stenosis at lumbar 4-5 level. She underwent discectomy with OIC cage insertion (Fig. 2). The Disc height was improved from $8.3 \mathrm{~mm}$ to $11 \mathrm{~mm}$ after surgery. After a year, height slightly decreased to $9 \mathrm{~mm}$ with suspicion of subsidence and the height maintained in $8 \mathrm{~mm}$ during 8 years of follow-up but had Grade I spondylolisthesis. Segmental lordosis before surgery was $15^{\circ}$ which have decreased to $13.3^{\circ}$ after surgery and increased to $18^{\circ}$ in 8 years of follow-up. Total lordosis before surgery was measured as $44.8^{\circ}$ which decreased in $42^{\circ}$ after surgery and gradually increased to $50^{\circ}$ after 8 years. Her VAS score before surgery was 8 for back pain and 5 for leg pain which decreased to score 0 for both. With confidence, excellent result in Odom's criteria.

\section{DISCUSSION}

Lumbar interbody fusion provides several theoretical advantages over other fusion techniques ${ }^{28,31)}$ including biomechanical stability with a higher fusion rate ${ }^{33)}$ and can create 



Fig. 2. (A) Pre-operative plain x-ray was taken. (B) Cages are inserted bilaterally without marked complication. (C) After a year, minimal subsidence is found in x-ray but patient had great clinical outcome. (D) Subsidence in L4 vertebra body is seen with mild retrolisthesis. Despite unsatisfying radiological outcome, patient had excellent clinical outcome.

the restoration of disc height and the sagittal balance ${ }^{26}$. Furthermore, since stand-alone PLIF needs less muscle retraction leading to less complications and post-operative pain ${ }^{10)}$. As Lumbar interbody fusion inserted posteriorly, the spinal canal can be easily explored. Furthermore, the use of locally derived bone obviates the need to harvest iliac bone or the amount of bone required for the graft ${ }^{27)}$. The disadvantages include interbody fusion Problems such as collapse, slippage, and graft migration in 3 to $10 \%$ of cases in major studies ${ }^{1,16}$. Particularly, in PLIF, dural and nerve root manipulations represents as a risk of this procedure ${ }^{11,15,17)}$. However, taken the above merits into account PLIF is still considered as a primary choice.

\section{Clinical Outcome}

The clinical outcome after PLIF can vary widely based on the selection criteria. As we chose to use VAS and Odom's criteria, the significant reduction of VAS was achieved at 1 year after surgery and the reduction of VAS lasted to follow-up periods even if it was found to be increased. These results are in agreement with a 2 year follow-up study ${ }^{19)}$. The analysis of Odom's criteria represents clinical outcomes indicating the maintenance of the successful clinical results with mid-term follow-up.

\section{Fusion Outcome}

Several studies indicate, the bone fusion rate of other interbody fusion methods are more than $90 \% \%^{3,16,22,24,25,32)}$. In the present study, the fusion rate was $91 \%$ at 4 years follow-up and found to be constant during subsequent years of followup. The fusion rate of stand-alone cage insertion may be lower than followed screw fixation. Compared with other standalone PLIF series $(85.2 \% \text { to } 86 \%)^{29,36}$, the result was better in this series but lower than pedicle screw fixation group $(91.1 \%)^{12)}$.

The fusion was confirmed by plain x-ray or CT scan. The flexion-extension film showed stability in all patients. As described by Fraser ${ }^{26}$, it is difficult to specifically ascertain the fusion rate in radiologic findings and a simple comparison for fusion rate is impossible without any criteria. Therefore, in this study, we used the criteria suggested by Burkus ${ }^{6}$.

\section{Disc Height, Subsidence and Lordosis}

Subsidence or spondylolisthesis with instability is the most common matter of concern after PLIF with stand-alone cage. In the present study there were differential subsidence in most cases but the subsidence was progressive up to 2 years postsurgery. The intervertebral disc height was reduced by approximately $6 \%$ after 4 years of surgery. However, the rate of subsidence was decreased to $2 \%$ per year. The data obtained in our studies showed a relatively early high subsidence rate and a late low subsidence rate in long-term follow up. The cage seemed to maintain the intervertebral disc height as well in the mid-term follow-up.

Interestingly, a lower subsidence rate (about 6.5\%) for 2 
year follow-up was also reported ${ }^{19)}$. This difference may be due to a difference between a rectangular cage and an expandable cage.

The physiological curve of the spine is related to the distribution of optimal weights loaded onto the spine and the loss of physiological curve in the lumbar spine is attributed to back pain $^{1,11,15,17,18,37}$. As suggested by Wambolt and Spencer ${ }^{27,18,21,34)}$, the destruction of lordosis results from the decrease in intervertebral disc height and interspinous ligament damage due to degenerative changes.

The segmental angle of lordosis was improved from 12.1 \pm $4.0^{\circ}$ to $10.3 \pm 5.8^{\circ}$ by postoperative 4 year. The angle was maintained for four years with no significant difference $(p=$ 0.179). In spite of using no lordotic angled cages in all cases, segmental lordosis was developed close to physiological lordosis, indicating subsidence of posterior vertebral body has played an important role in making the angle. However, at the forth year follow-up segmental angulation was reduced significantly.

Total lumbar lordosis found to be changed from $32.8 \pm$ $10.2^{\circ}$ to $36.0 \pm 8.1^{\circ}$ at the four years of follow-up. It may be suggested that the segmental angle recovery of the lower lumbar spine is not the only factor in deciding the total lumbar lordosis recovery, however, it is important in the development of the facet joint degeneration, ligament hypertrophy, and back muscle atrophy. The significance of these factors was not evident in this study ${ }^{19}$.

\section{Complications}

Complications associated with PLIF can be serious, especially the neurological deficits often related to excessive retraction of the nerve roots or the dural sac. According to the various reports, these complications occur in 4 to $10 \%$ of patients ${ }^{16,22,31)}$. As reported by Kuslich et al., ${ }^{22)}$ the complication of cage migration was observed in 3\% of the patients. Additionally, increasing numbers of cage migration is reported when stand-alone cages were used. Though repeated migration of cage after posterior lumbar interbody fusion has been reported $^{23)}$, the rate of cage migration in patients with no posterior instrumentation was significantly higher compared with the rate in those with posterior instrumentation $(16.7 \%$ vs. $0 \%)^{30)}$. We have observed relatively low of perioperative complications including hardware problems after PLIF using stand-alone cages, which could be due to low rate of cage retropulsion, may be related to the threaded cage appearance.

\section{Study Limitation}

There are several limitations in this study which include is only a retrospective review in which preoperative functional data on the patients are not available and lack of adequate clinical follow-up. The correlation between plain radiographic fusion and actual fusion was also not well established as described earlier ${ }^{10,30)}$.

\section{CONCLUSION}

We have investigated for the first time, the safety and efficacy of the rectangular cage in the degenerative lumbar spinal disorders. The use of rectangular stand-alone cages for PLIF resulted in a various degree of subsidence. However, the progress of subsidence was halted as fusion progresses despite of using no lordotic angled cages. Segmental lumbar lordosis was naturally developed close to physiological lordosis suggesting that subsidence of posterior vertebral body may have played an important role in making the angle. Results of this study demonstrate very low complications of the cage during the follow-up periods, high functional stability, improved clinical outcomes in patients with degenerative lumbar disc disease.

\section{REFERENCES}

1. Agazzi S, Reverdin A, May D: Posterior lumbar interbody fusion with cages: an independent review of 71 cases. J Neurosurg 91:186-192, 1999

2. Bernhardt M, Bridwell KH: Segmental analysis of the sagittal plane alignment of the normal thoracic and lumbar spines and thoracolumbar junction. Spine (Phila Pa 1976) 14:717-721, 1989

3. Brantigan JW, Steffee AD: A carbon fiber implant to aid interbody lumbar fusion. Two-year clinical results in the first 26 patients. Spine (Phila Pa 1976) 18:2106-2107, 1993

4. Brodke DS, Dick JC, Kunz DN, McCabe R, Zdeblick TA: Posterior lumbar interbody fusion. A biomechanical comparison, including a new threaded cage. Spine (Phila Pa 1976) 22: 26-31, 1997

5. Burkus JK, Gornet MF, Dickman CA, Zdeblick TA: Anterior lumbar interbody fusion using rhBMP-2 with tapered interbody cages. J Spinal Disord Tech 15:337-349, 2002

6. Burkus JK, Gornet MF, Schuler TC, Kleeman TJ, Zdeblick TA: Six-year outcomes of anterior lumbar interbody arthrodesis with use of interbody fusion cages and recombinant human bone morphogenetic protein-2. J Bone Joint Surg Am 91:1181-1189, 2009

7. Chernukha KV, Daffner RH, Reigel DH: Lumbar lordosis measurement. A new method versus Cobb technique. Spine (Phila $\mathrm{Pa}$ 1976) 23:74-79; discussion 79-80, 1998

8. Chitnavis B, Barbagallo G, Selway R, Dardis R, Hussain A, Gullan R: Posterior lumbar interbody fusion for revision disc surgery: review of 50 cases in which carbon fiber cages were implanted. J Neurosurg 95:190-195, 2001

9. Diedrich O, Luring C, Pennekamp PH, Perlick L, Wallny T, Kraft CN: [Effect of posterior lumbar interbody fusion on the lumbar sagittal spinal profile]. Z Orthop Ihre Grenzgeb 141: 
425-432, 2003

10. Eck KR, Bridwell KH, Ungacta FF, Lapp MA, Lenke LG, Riew $\mathrm{KD}$ : Analysis of titanium mesh cages in adults with minimum two-year follow-up. Spine (Phila Pa 1976) 25:2407-2415, 2000

11. Fernand R, Fox DE: Evaluation of lumbar lordosis. A prospective and retrospective study. Spine (Phila Pa 1976) 10:799803, 1985

12. Fogel GR, Toohey JS, Neidre A, Brantigan JW: Outcomes of posterior lumbar interbody fusion with the 9-mm width lumbar I/F cage and the variable screw placement system. J Surg Orthop Adv 18:77-82, 2009

13. Godde S, Fritsch E, Dienst M, Kohn D: Influence of cage geometry on sagittal alignment in instrumented posterior lumbar interbody fusion. Spine (Phila Pa 1976) 28:1693-1699, 2003

14. Goh JC, Wong HK, Thambyah A, Yu CS: Influence of PLIF cage size on lumbar spine stability. Spine (Phila Pa 1976) 25: 35-39; discussion 40, 2000

15. Hansson T, Bigos S, Beecher P, Wortley M: The lumbar lordosis in acute and chronic low-back pain. Spine (Phila Pa 1976) 10: 154-155, 1985

16. Hutter CG: Posterior intervertebral body fusion. A 25-year study. Clin Orthop Relat Res:86-96, 1983

17. Itoi E: Roentgenographic analysis of posture in spinal osteoporotics. Spine (Phila Pa 1976) 16:750-756, 1991

18. Jackson RP, McManus AC: Radiographic analysis of sagittal plane alignment and balance in standing volunteers and patients with low back pain matched for age, sex, and size. A prospective controlled clinical study. Spine (Phila Pa 1976) 19:1611-1618, 1994

19. Kim JW, Park HC, Yoon SH, Oh SH, Roh SW, Rim DC, et al: A Multi-center Clinical Study of Posterior Lumbar Interbody Fusion with the Expandable Stand-alone Cage (Tyche (R) Cage) for Degenerative Lumbar Spinal Disorders. J Korean Neurosurg Soc 42:251-257, 2007

20. Klemme WR, Owens BD, Dhawan A, Zeidman S, Polly DW, Jr.: Lumbar sagittal contour after posterior interbody fusion: threaded devices alone versus vertical cages plus posterior instrumentation. Spine (Phila Pa 1976) 26:534-537, 2001

21. Korovessis PG, Stamatakis MV, Baikousis AG: Reciprocal angulation of vertebral bodies in the sagittal plane in an asymptomatic Greek population. Spine (Phila Pa 1976) 23:700-704; discussion 704-705, 1998

22. Kuslich SD, Danielson G, Dowdle JD, Sherman J, Fredrickson B, Yuan $\mathrm{H}$, et al: Four-year follow-up results of lumbar spine arthrodesis using the Bagby and Kuslich lumbar fusion cage.
Spine (Phila Pa 1976) 25:2656-2662, 2000

23. Lee JG LS, Kim SW, Shin H: Repeated Migration of a Fusion Cage after Posterior Lumbar Interbody Fusion. Korean J Spine 10:25-27, 2013

24. Lehmann TR, Spratt KF, Tozzi JE, Weinstein JN, Reinarz SJ, elKhoury GY, et al: Long-term follow-up of lower lumbar fusion patients. Spine (Phila Pa 1976) 12:97-104, 1987

25. Ma GW: Posterior lumbar interbody fusion with specialized instruments. Clin Orthop Relat Res:57-63, 1985

26. McAfee PC: Interbody fusion cages in reconstructive operations on the spine. J Bone Joint Surg Am 81:859-880, 1999

27. Mizuno J, Nakagawa H: Threaded fusion cage for lumbar spondylolisthesis. Neurol Med Chir (Tokyo) 38:155-160, 1998

28. Onesti ST, Ashkenazi E: The Ray Threaded Fusion Cage for posterior lumbar interbody fusion. Neurosurgery 42:200-204; discussion 204-205, 1998

29. Park JH, Roh SW: Long-term clinical and radiological outcomes following stand-alone PLIF surgery using expandable cylindrical threaded cages in patients with degenerative lumbar spine disease. Acta Neurochir (Wien) 153:1409-1416; discussion 1416, 2011

30. Pellise F, Puig O, Rivas A, Bago J, Villanueva C: Low fusion rate after L5-S1 laparoscopic anterior lumbar interbody fusion using twin stand-alone carbon fiber cages. Spine (Phila Pa 1976) 27:1665-1669, 2002

31. Ray CD: Threaded titanium cages for lumbar interbody fusions. Spine (Phila Pa 1976) 22:667-679; discussion 679-680, 1997

32. Rish BL: A comparative evaluation of posterior lumbar interbody fusion for disc disease. Spine (Phila Pa 1976) 10:855-857, 1985

33. Schlegel KF, Pon A: The biomechanics of posterior lumbar interbody fusion (PLIF) in spondylolisthesis. Clin Orthop Relat Res:115-119, 1985

34. Tencer AF, Hampton D, Eddy S: Biomechanical properties of threaded inserts for lumbar interbody spinal fusion. Spine (Phila Pa 1976) 20:2408-2414, 1995

35. Tribus CB, Belanger TA, Zdeblick TA: The effect of operative position and short-segment fusion on maintenance of sagittal alignment of the lumbar spine. Spine (Phila Pa 1976) 24:58-61, 1999

36. Tullberg T, Brandt B, Rydberg J, Fritzell P: Fusion rate after posterior lumbar interbody fusion with carbon fiber implant: 1-year follow-up of 51 patients. Eur Spine J 5:178-182, 1996

37. West JL, 3rd, Bradford DS, Ogilvie JW: Results of spinal arthrodesis with pedicle screw-plate fixation. J Bone Joint Surg Am 73:1179-1184, 1991 